\title{
Mission Statements of Japanese Civil Society Organizations Supporting International Students in the Kansai Area: Critical Discourse Analysis
}

\author{
Polina Ivanova ${ }^{\mathrm{a}^{*}}$ \\ ${ }^{a}$ Ritsumeikan University, Japan \\ *Correspondence: gr0162@ed.risumei.ac.jp
}

\begin{abstract}
This study is applying critical discourse analysis (CDA) to mission statements of civil society organizations (CSOs) in the Kansai area of Japan to examine how those texts may be reflecting their views on migration and impacting their practices related to international students. The analysis shows similarities across CSO types in choosing organizational names, using vague and bureaucratic vocabulary for formulating their mission statements, as well as confusing and contradictory style of some statements and event announcements that may be misleading or discouraging for potential members. At the same time, diversity of vocabulary referring to their target audience demonstrates shifting perspectives of CSOs on international students and more generally, on foreigners living in Japan.
\end{abstract}

Keywords: civil society organizations (CSOs), critical discourse analysis (CDA), Japan, international students, mission statements

\section{INTRODUCTION}

Japan is actively attracting international students into its higher education institutions as a part of its large-scale internationalization reforms initiated by the government in the $1980 \mathrm{~s}$ and designed to transform Japan into an "international nation" (Otmazgin, 2018). The country is currently on the way to realize its 300,000 International Student Plan, meaning recruiting 300,000 international students by the year 2020. Besides benefitting the educational sphere, this initiative also helps to impact domestic factors in Japan, such as an aging and shrinking population growing demand for skilled human resources by Japanese companies to remain internationally competitive, and provides important incentives for internationalization (METI, 2018, 2019). To respond to these challenges, local governments are implementing a variety of international student support initiatives both via universities and directly, often with the help of their affiliated volunteer groups (see, for instance, Kyoto City, 2014; Kyoto City, 2020).

\section{Internationalization of Higher Education in Japan}

Numerous studies have focused on internationalization policies at Japanese universities (Knight, 2004, 2008; Ninomiya, Knight \& Watanabe, 2009; Horie, 2015; Poole, 2016), university support system for incoming foreign students (Bradford, 2015; Rakhshandehroo \& Yamamoto, 2017), international students' experiences on campus (Mock et al., 2016; Rakhshandehroo, 2018) and their strategies to cope with cultural adjustment (Mock et al., 2016; Shimauchi, 2017, 2018). However, the impact of third parties, such as onand off-campus volunteer organizations on international students' sociocultural adaptation, has not been sufficiently studied.

Received January 26, 2020; revised June 8, 2020; August 1, 2020; accepted October 1, 2020; electronically published May 1, 2021

Journal of Comparative \& International Higher Education

May, 2021, Vol. 13, No. 2, pp. 38-52.

DOI: $10.32674 /$ jcihe.v13i2.1890

(C) 2021 Journal of Comparative \& International Higher Education. All rights reserved. 


\section{Civil Society in Japan}

This paper relies on Pekkanen's (2006) definition of civil society as “organized, non-state, non-market sector" (p. 3). Although Japanese civil society has a long history of its own, it has been excluded from the postwar "iron triangle" (a close partnership between the ruling party, state bureaucracy and big businesses) and the law allowing citizens to register their own nonprofit organizations was passed only in 1998, much later than in other developed countries. Instead of contesting public policies like their Western counterparts, Japanese civil society organizations (CSOs) learned how to cooperate with the government; they are characterized by their top-down nature (Schwarz \& Pharr, 2003; Ogawa, 2009; Reimann, 2010; Tsujinaka, 2010 ) and their predominant orientation towards service provision rather than political advocacy (Vogt \& Lersch, 2007) which makes Pekkanen call them "members without advocates" (2006). The purpose of this paper is to critically examine mission statements of Japanese CSOs engaged with incoming foreign students and uncover underlying assumptions they hold regarding themselves and cultural "others" that could have an impact on the ways they interact with international students. The organizations in this sample are small local nonprofits and volunteer groups that are involved with international students in a variety of ways: sightseeing tours, cultural experiences, community activities, language classes or exchange, daily life support and career guidance. Although there is a greater variety among international student support CSOs (Ivanova, 2000), the organizations in this sample can be classified into three types for the purposes of this study: 1) CSOs initiated and funded by local governments, 2) CSOs initiated and funded by the MEXT (Ministry of Education, Culture, Sports, Science and Technology), and 3) university-affiliated student groups. Using Haddad's terminology, these types could be called "embedded organizations" as those having "close, ongoing relationships with the government" (Haddad, 2007, p. 164) directly or through universities as mediators. This confirms a dominant view in civil society studies that Japanese CSOs are wide-spread and active but because of its top-down character and close affiliation to the government their role remains reduced to that of implementing agencies (Schwarz \& Pharr, 2003; Ogawa, 2009; Reimann, 2010). This paper focuses on CSOs that are active in four prefectures in the Kansai area, or Western Japan: Shiga, Kyoto, Osaka, and Hyogo. This area is Japan's historic heartland, a major economic center and home to numerous national and private universities attracting international students who also receive much attention from local volunteer organizations. Although all the organizations have some form of online presence (typically, a website and/or a Facebook page), this paper is only limited to those having their webpage or Facebook page written in English, the main language of the globalization and one of the main internationalization strategies in Japan as in many other non-English speaking countries (Dearden, 2014; Macaro et al., 2018). The terms CSOs, nonprofits, volunteer organizations and student support groups are used in this paper interchangeably as synonyms.

\section{LITERATURE REVIEW}

\section{Mission Statements}

The mission statement is defined as "a written, formal document that attempts to capture an organization's unique and enduring purpose and practices" (Bart \& Tabone, 1998, as cited in Barniskis, 2016, p. 136). Researchers have noted the ubiquitous character of mission statements (Morphew \& Hartley, 2006) and their critical role for organizations, in relation to both insiders and outsiders. Several studies (Drucker, 1989; Pandey, Kim \& Pandey, 2017; Macedo, Pehno \& Silva 2017) have demonstrated that mission statements are closely related to the organizational performance, although this relationship may be 
indirect, mediated by employees' organizational commitment (Macedo, Pehno \& Silva 2017). Although mission statements do not always reflect objective reality and researchers question whether mission statements are strategic necessity or window dressing (Souder, 2016), these texts certainly almost reveal how organizations would like to be perceived from the outside.

Another group of studies has identified typical components of mission statements. Bartkus, Glassman \& McAfee (2004) have formulated three criteria that organizational mission statements should fulfill: 1) identifying specific stakeholder groups, 2) including specific components (industry, geographic scope, values, competence, motivational messages, future orientation) and 3) achieving four objectives: communicating direction, assisting in control, guiding decision-making and motivating employees (p. 393). Based on their analysis of mission statements of American universities, Morphew \& Hartley (2006) added to that list that mission statements can reflect organizational aspirations.

A number of studies (Chen \& Collier, 2012; Woolford \& Curran, 2012) have applied critical discourse analysis (CDA) to data coming from interviews with nonprofit employees in the US and Canadian contexts. CDA is an interdisciplinary approach interested in language as "social practice" (Fairclough \& Wodak, 1997, as cited in Wodak, 2007, p. 209) and focusing on issues of power, ideology, domination and control (Wodak, 2007). In Chen \& Collier's study, the approach was instrumental in uncovering how contradictory avowals (group members' representations to the outsiders) and ascriptions (representations of other groups) undermine the organizations' potential to serve the affected groups and fulfill their purpose (Chen \& Collier, 2012, p. 45). Woolford \& Curran (2012) have used CDA to show how indigenous reflexive practices and transpositions (ability of social actors to transfer their practices from one field to another) at nonprofits were able to counteract the dominant neoliberal welfare approach. These studies, however, have not focused on mission statements.

Some other researchers studied mission statements in the nonprofit sector but applied different methods of analysis (content analysis, thematic analysis, quantitative methods using software). Lawless (2012) described how mission statements of the US nonprofits focusing on poverty alleviation reflected the dominant ideology that individuals should be able to help themselves (Lawless, 2012, pp. 13-14). Dimitrov (2008) finds problematic that mission statements of many nonprofits look alike; this is also true for most Japanese CSOs in this study. Another challenge for mission statements is their need to handle "strategic ambiguity" (Dimitrov, 2008, p. 22); he sees a solution for this problem in creating specific messages for specific purposes and public while maintaining a general mission statement representing the raison d'être of an organization as a whole.

A comparative analysis of European, Japanese and US mission statements done by Bartkus, Glassman \& McAfee (2004) revealed that Japanese companies were more likely to motivate employees by stating how their business can improve the society while US and European emphasized competitive superiority (p. 399). This tendency was explained by the collectivist value orientation of the Japanese as opposed to more individualistic Westerners.

\section{Perceptions of Migration in Japan}

This section highlights several factors influencing perceptions of migration and foreigners in Japan to better understand the context in which student-support CSOs are operating. According to Beciu et al. (2017), state institutions and policies adapt to migration by modifying their discourse and creating a sense of solidarity with migrants in order to retain their power status (Beciu et al., 2017, p. 231). This tendency may be true for some migrant support organizations in Japan focusing on political advocacy; however, most 
organizations from the present sample view themselves mainly as service providers to foreigners who are generally perceived as guests or temporary visitors. This view is in line with Nihonjinron ideology, a form of cultural nationalism, literally meaning: "discussions of the Japanese" and summarized by Stevens (1997) as follows: 1. Japanese are "culturally and socially homogenous," 2. They are different from Westerners and also other Asian people, 3. They can only be analyzed by means of Japanese social theories (Stevens, 1997, p. 12). The first presupposition clearly fails to take into account many population categories, such as Japanese residents of Chinese and Korean descent, Ainu and Okinawan populations, foreign workers including Japanese returnees born overseas, children from international marriages and international students, among others. Historically, the myth of homogeneity of the Japanese was exploited by the authorities starting from the Meiji era to create nationalistic and militaristic ideology; since then, it has also spread across the world and continues to impact Japanese citizens' perceptions of migration until today (Lie, 2001; Takeuchi, 2006; Burgess, 2010).

Another factor affecting perception of foreigners in Japan was a period of isolation in Japanese history, a so-called "Sakoku" lasting from 1633 till 1853 when the country was forcibly opened by the Commodore Perry had a deep impact on Japanese mentality and resulted in a number of fears and myths regarding foreigners, especially of non-Asian origin. The folklore classic The Legends of Tono by Kunio Yanagita (1910) includes stories of Western visitors among those of ghosts and of Tengu, long-nosed mountain goblins (Yanagita, 1910, 2008). Later, Japan's defeat in the World War II, American occupation, and postwar economic progress (a so-called "Japanese economic miracle") made Japanese more exposed to the rest of the world but not necessarily more willing to accept cultural differences. During the Sakoku period, Japanese authorities allowed a limited number of non-Asian foreigners to stay on an artificial island near Nagasaki called Dejima. Based on the analogy with the historical island, Shimauchi (2017) coined a term "dejimaization" to describe the current situation of isolation experienced by international students and faculty in Japanese universities. Civil society groups have the potential to tackle this issue of isolation by creating new ties among people that would not have met in their ordinary life without the mediation of volunteer groups (Ogawa, 2009; Vinken et al., 2010).

This paper appears to be the first attempt to apply CDA to Japanese CSOs' mission statements written in English and analyze how these texts may be reflecting their views on migration and impacting their practices related to international students.

\section{METHODOLOGY}

Methodologically, this study uses critical discourse analysis (CDA), a cross-disciplinary inquiry analyzing language as a social practice and uncovering the ways discourse reproduces existing ideology, social inequalities, and domination (Fairclough, 1989). Both spoken and written texts can be analyzed by means of CDA; however, unlike a conventional document analysis, CDA does not stop at the micro-level, i.e., syntactic, semantic, or rhetorical structures shaping the text. As a "socially committed research," (Lin, 2014) it proceeds to relating those specific language structures to the broader sociopolitical context by studying issues related to text production: institutions producing a text and its target audience, its purpose and processes of its production, distribution and consumption. CDA was chosen for this study due to its potential to reveal presuppositions underpinning representations of international students and selfrepresentations among Japanese CSOs and understand how those assumptions may impact organizational practices. 
As the previous section has shown, CDA has been frequently applied in migration studies to deconstruct the dominant discourse by identifying presuppositions related to cultural "others" and by uncovering ways certain migrant-related issues are framed in media, public documents, education or advertising.

Mission statements of Japanese CSOs have been analyzed to see how the organizations represent themselves and their service recipients, i.e., foreigners in Japan. This study focuses on mission statements written in English because they are mostly accessible for international students studying in Japan in Englishmedium programs (EMP) and are the main way of introducing the organization to the target audience. Mission statements in English play a role of signposts or sign boards for students allowing them to make informed choices as for joining CSOs and their events.

The mission statements of international student support groups are often embedded in a broader selfdescription, along with organizational history, contact information and event announcements. Although most CSOs in this sample employ English native speakers as their staff or volunteers; however, it remains unclear to what extent they make use of their services while presenting their website materials as the quality of their writing varies considerably. Sometimes, their sentences contain grammar mistakes, seem stylistically unclear or look like direct translation from Japanese. Consequently, it is uncertain how conscious their vocabulary choice is and to what extent the organizations are aware of the pragmatic effect these texts might create. In those cases, some ways of expression may be unintentional, and results should be interpreted with caution.

\section{DATA ANALYSIS}

The analysis focused primarily on lexicosemantic components of mission statements using qualitative approach and following these steps. First, websites of thirty organizations involved with international students across four prefectures of Japan were accessed in June 2019. Eleven out of thirty CSOs provided mission statements in English and they were therefore selected for this study. Next, an open coding was performed to break down selected texts into units and develop categories using inductive approach (Patton, 2002; Bengtsson, 2016). A qualitative content analysis focused on lexicosemantic components of mission statements for manifest analysis of surface structures ("What has been said?") and latent analysis of deep structures ("What was the author's intention?"). The content analysis highlighted which vocabulary units were used to operationalize mission statements and how the meaning of these words and expressions helped the organization to convey their message or prevented it from doing so. To complement the content analysis, the thematic analysis was used to identify recurrent themes in the mission statements (Patton, 2002; Hsieh \& Shannon, 2005; Johnson \& Christensen, 2014). The themes that emerged from the data were classified into three main groups: "organization mission and role," "key stakeholders," and "organizational values." Connecting the findings of content and thematic analyses allowed to unravel how the word choice of CSOs helped them express their unique purpose and/or their conformity to the established standards of international student support.

Furthermore, creating a simple typology based on organizational structure allowed to review tendencies in mission statements within each type and across the types. Among the eleven CSOs in the sample, only KyoTomorrow Academy belongs to the second type (sponsored by the MEXT) while Osaka University International Student Association (OUISA), Ritsumeikan Graduate Student Association(GSA) and Ritsumeikan Tutors for International Students' Assembly at Osaka Ibaraki Campus (OIC TISA) belong to 
the third type (university-affiliated groups) and the remaining seven organizations belong to the first type (affiliated with local governments).

The first draft of this paper was shown to an expert in pragmatics and applied linguistics a native English speaker to check the validity of the author's interpretations and enhance the trustworthiness of research results.

\section{FINDINGS}

\section{Similarities in Organizational Names and Mission Statements}

The first noticeable feature is the similarity among the CSO names: four of them are called "International Association," three others "International Friendship Association" preceded by the name of the town or city, and two more are "International Foundations." One possible explanation is that they may be learning best practices from each other, and the similarity occurs naturally in the process of knowledge transfer. Alternatively, this may also be due to the top-down nature of the CSOs as they are named by government officials following a similar pattern. It is not possible to give a definite answer to this question with the available data; however, the similarity itself may be also serving a purpose as it reinforces the impression of uniformity and "homogeneity" cherished by the Japanese establishment. University-affiliated groups or those targeting specifically international students (KyoTomorrow Academy) display more diversity in their names using other nouns such as Assembly or Academy.

Similarities are also found in their ways of formulating their mission statements. Most CSOs in the sample exhibit their mission statement as a short phrase at the top of their homepage or "About" section in their Facebook profile. However, in the case of Yasu City International Friendship Association, the mission statement is modestly hidden at the bottom of the page below the address, contact information and map. It refers to the town history (the merge of two towns into one) before engaging into the usual rhetoric of "smooth integration," apparently meaning that foreigners should become a part of Japanese society without destroying its inherent "harmony." Nakamatsu (2014) believes that the Japanese government prioritizes "stability over inclusiveness" (p. 142) and interprets constant referring to "living together in harmony" in the official discourse as attempts to conceal existing power inequality for the sake of harmony (Nakamatsu, 2014, p. 140). This points to the vast contrast in culture of Japan and the West, and can be seen in the ways local CSOs represent these cultural values in their mission statements.

\section{Variations in Referring to Stakeholders}

On the other hand, much more variations can be observed in the ways the CSOs refer to their stakeholders, clients or target audience: they are called "foreigners," "foreign residents," "foreigners living in the local area," "visitors from overseas," "citizens of the world," "international students," "members" and "people with diverse cultural background." Such diversity in terminology can demonstrate shifting perspectives on foreign residents in Japanese society after the recent emergence of multiculturalism discourse (Tsuneyoshi, 2011; Lee \& Olsen, 2015; Bradley, 2016). In the past, they would be called only "foreigners" or "visitors" and perceived as temporary guests; somewhat later the "international students" category was added, and more recently, when "multicultural coexistence" became buzzwords in the Japanese media, such expressions as "citizens of the world" and "people with diverse cultural background" were brought up. 


\section{Lexicosemantic Operationalization of Mission Statements}

Perhaps unsurprisingly, the most common word used to operationalize mission statements is "international" used 43 times throughout the sample texts in combination with nouns as "exchange," "understanding," "relationships," "friendship," "cooperation," and "communication" showing the organizational purpose. Next widely used words are "activity/activities" used eight times to point to the action-oriented nature of the CSOs, "support" and "culture," also used eight times including their derivatives like "cultural" or "multicultural." The popularity of the word "culture" may be explained by the emphasis on cultural differences rather than similarities that is dominant in Japanese media, official discourse, and mainstream thinking. The word "support" may also reflect paternalistic ideas of Japanese society that foreigners need to be supported and educated in order to "live in harmony" in the Japanese society, or another variation elsewhere: "live at ease with foreigners." The word "community" has been used four times which shows that there might be a growing attention to including newcomers into the community life. Other key words ("foreign," "global," "diversity," "smooth," "harmony," "connect") are used two or three times only. Overall, mission statements of the organizations of the first type (affiliated to the local government) present the same narrative of the "peaceful coexistence with foreigners" that can be interpreted as attempts to "tame" newcomers through providing some activities and educating them to behave in a way that would not disturb steady functioning of the local community.

Among activities provided by the CSOs, there have not been found any events or workshops on controversial topics (migration, sexual minorities' rights, gender gap) or those that could potentially undermine the international image of Japan (dealing with consequences of Fukushima nuclear meltdown, whaling practices, mental health issues, racism at schools or exploitation of "technical trainees," low-paid foreign workers from South-East Asia). The ways Japanese culture is represented through the CSOs activities: cooking events, sightseeing, language classes for beginners, seem superficial and limited to those aspects of culture that have been judged by the CSO decision-makers as safe and attractive. Being overly concerned with making a good impression on foreigners, CSOs opt for "kireigoto," literally meaning "beautiful or clean things" that can be shown to outsiders (Stevens, 1997).

\section{Differences across Types}

The CSOs of the first group often refer to their sister cities, usually those in the United States. This could be seen as a geopolitical marker and a way to legitimize themselves as Japanese society and culture have been considerably Americanized and virtually everything related to the US is perceived in Japan as inherently superior. It could also serve as a reference to the organizational evolution and history: many of the CSOs in smaller towns were founded in relation to a partnership agreement as an attempt of local authorities to engage citizens in welcoming foreign visitors to their town and encourage them to visit their sister city in turn. This history of interaction in form of exchanging visits may also explain the prevalence of the phrase "international exchange" in the mission statements.

The second type (sponsored by MEXT) is represented by only one organization KyoTomorrow Academy. Unlike the first type open to all categories of foreigners in Japan (tourists, spouse visa holders, missionaries, trainees, English teachers or company employees), KyoTomorrow focuses uniquely on international students studying in Kyoto City and aims to provide employment support to those who would like to find a job in Kyoto after graduation.

The main problem of their mission statement is that it does not articulate the organizational purpose

clearly enough. After a good starting sentence mentioning "international students" and "employment," they 
continue by saying that students can participate in "traditional cultural activities" that they "wouldn't find anywhere else." This statement is confusing because the main purpose of the group is not providing cultural activities, and secondly, it sounds misleading because there are multiple CSOs in Kyoto City that organize tea ceremony demonstrations, kimono-wearing sessions, calligraphy classes and similar events that can be classified as "traditional cultural activities." Since incoming international students are usually bombarded with various invitations from volunteer groups, they may easily overlook the message from KyoTomorrow, which is the only organization in its genre focusing on long-term support and integration instead of merely entertaining activities.

The third group is represented by three student support organizations initiated and run by universities. They are managed differently: Osaka University International Student Association (OUISA) is run primarily by international students, Ritsumeikan OIC TISA is operated almost entirely by domestic Japanese students recruited by the university to organize events with international students, and Ritsumeikan GSA includes both international and domestic students with more focus on academic affairs rather than social life. Mission statements of both Ritsumeikan-affiliated groups are written in the same vague bureaucratic style as most statements of the first group, while OUISA's mission statement differs from them in a somewhat problematic way.

The text starts by inviting the audience to reach out for "fun stuff" in a sentence that sounds quite relaxed and friendly; however, the number of restrictions mentioned in the introduction may discourage the reader to do so. A disclaimer "We basically do not respond to the requests from OUTSIDE (sic) Osaka University" is repeated twice with the word "outside" written in all capitals, and after each bullet point, there is another statement in brackets ("most of our activities are for Osaka University students only"). These contradictory statements in introduction and mission statements may represent the conflict between some willingness to open up and support international students, on one hand, and tight institutional control, on the other hand. In particular, these restrictions may be problematic for those students who come to study with their families and would like to bring them to a party or an event, or if someone wishes to invite their friends from another university.

Another notification states: "We generally do not take requests for assistance (help about life in Japan, interpreting, guiding etc.)" which may also seem unfriendly and hostile from a student support organization, particularly if read by international students who recently arrived and are experiencing confusion and discomfort in their transition process. The final reminder: "Studies are the most important work for any international student, so you are welcome to participate when you have time from studies" can be interpreted as "Don't forget you are here to study, not to have fun" and may be seen as patronizing and unpleasant by some international students. This section is also interesting from the viewpoint of politeness pragmatics and shows how cross-cultural misunderstandings may arise from the differences in politeness perceptions in different cultures.

\section{Organizational Roles and Values in Mission Statements}

The organizational roles across the three types are described as "a base for international exchange" (Kyoto City International Foundation), "a community for international students" (KyoTomorrow Academy), "a student circle" (OUISA), "a core organization for international relationship and multicultural coexistence" (Miki City International Association), "facilitating international communication of the city" (Nishinomiya International Association), "an official organization which mission is to represent and defend the student's interests" (Ritsumeikan GSA) and "an organization of Ritsumeikan University" (Ritsumeikan 
OIC TISA). Some of those self-definitions or role description clearly point to organizational values: for instance, "an official organization" sounds more formal than "a student circle" and demonstrates a sense of pride in achieving an official status which requires a significant amount of time and paperwork in Japanese universities. Similar inference can be made regarding a self-definition of Miki City organization that displays the most updated vocabulary of Japanese multiculturalism.

In contrast, some other role descriptions or self-definitions are more difficult to interpret. For instance, the word "community" used by the KyoTomorrow Academy sounds definitely much friendlier than the "base" (Kyoto City International Foundation) that reminds of a military base; however, it is not clear whether the word choice is intentional and reflects certain organizational values. Authors of mission statements of the CSOs remain unknown, which allows to apply the theory of "vanishing author" proposed by Gergen and Whitney in regard to mission statements of IT firms when anonymous writers of the company mission become a "center" and "ultimate referent of the dominant discourse" (Gergen \& Whitney, 1996, as cited in Hackney \& Pillay, 2002).

\section{DISCUSSION}

This paper reviewed mission statements of international student support organizations in the Kansai area of Japan using qualitative discourse analysis. The analysis has shown similarities among CSO names and word choice to operationalize their mission statements. Other common points included abundance of vague and bureaucratic language, and frequent use of confusing and contradictory messages to describe the organizational purpose or events.

On the other hand, there was a considerable variation in terminology referring to CSO target audience which could demonstrate evolving attitudes to foreigners in Japanese society or, at the very least, CSOs' awareness of the government discourse of multicultural coexistence. In practice, most CSOs maintain the same approach to international students as they would have used for entertaining guests: the choice of activities is superficial and is limited to safe and pleasant topics.

The self-description of organizational roles and values also demonstrate considerable diversity: from simply indicating the organizational purpose to showing pride in the achieved status or awareness of the current government policies regarding foreign residents.

The CSOs of the first type refer to their sister cities in the United States in their mission statements as a way to legitimize their status and highlight their organizational history. While these organizations are open to all foreigners in Japan, those of the second and third types focus only on international students. The organization of the second type sponsored by the MEXT is unique in its mission of providing long-term integration support to international students through job-hunting support; however, their mission statement and event descriptions do not make their purpose clear and can easily remain unnoticed by the target recipients. The mission statements of university-affiliated organizations (third type) include contradictory messages that intend to encourage students to have fun and build trust but also point to the institutional control that some students might experience as discouraging. Overall, mission statements of the CSOs in this study uncover organizational attempts to maintain a fine balance between building trust and international friendships, on one hand, and following the government guidelines and restrictions, on the other hand. 


\section{CONCLUSION}

This paper contributes to the sociology of education and migration studies by analyzing mission statements of Japanese civil society organizations supporting inbound international students in their sociocultural adaptation. Despite the importance of mission statements for international students, only a minority of organizations involved with international students have them posted online in English (11 out of 30 CSOs). The analysis has shown similarities across types in choosing organizational names, frequent use of vague and bureaucratic vocabulary for formulating mission statements confusing and contradictory style of some statements that may be misleading or even discouraging for potential members. Therefore, it is advisable that CSOs working with international students choose clearer messages capable of attracting and inform their stakeholders and motivate their own volunteers and employees.

The data shows that some CSOs still view foreigners in Japan, including international students as temporary visitors in need of protection and support or even as potential threat and disruption to "smooth" and "harmonious" functioning of the Japanese society, while others use a more contemporary terminology that might attest some changes in their views on migrants in Japan. However, their approach to interaction between Japanese and foreigners remains largely the same regardless of their vision and structure, with a notable exception of KyoTomorrow Academy focusing on long-term integration. The main emphasis is on differences and diversity, not on unity or equity, and most intercultural activities are done on a very superficial level related to the visible part of culture: examples of popular activities include cooking classes and sightseeing tours; controversial issues and thought-provoking topics are carefully avoided.

The limitations of the study include a small sample size (only eleven organizations) and the fact that mission statements in English could have been written by non-native speakers of English, the word choice might have been unintentional and therefore, interpretations of the discourse should be made with caution.

Further research is needed to determine who chooses mission statements, to what extent CSO staff and volunteers have a sense of ownership vis-à-vis their organizational statements or whether they feel those statements have been imposed upon them by authorities or anonymous writers, and most importantly, whether they see a possibility of interaction between Japanese and foreigners on equal terms.

\section{ACKNOWLEDGEMENT}

The author would like to thank Dr. Jill Murray, lecturer in Pragmatics and Intercultural Communication at Macquarie University for her guidance in preparing the first draft of this paper, and Dr. Rosalind Latiner Raby and anonymous reviewers for their insightful comments.

Polina Ivanova is a Ph.D. candidate at the graduate school of International Relations of Ritsumeikan University, Kyoto, Japan. Her research focuses on international education and civil society in Japan and Australia.

\section{REFERENCES}

Barniskis, S. C. (2016). Deconstructing the mission: A critical content analysis of public libraries mission statements. The Library Quarterly: Information, Community, Policy, 86(2), 135-152. https://www.journals.uchicago.edu/doi/abs/10.1086/685403 
Bartkus, B. R., Glassman, M. \& McAfee, R.B. (2004). A Comparison of the quality of European, Japanese and US mission statements: A content analysis_European Management Journal, 22(4), 393-401. doi: 10.1016/j.emj.2004.06.013

Beciu, C., Mădroane, I. D., Cârlan, A. I. \& Ciocea, M. (2017).Power relations, agency and discourse in transnational social fields. Critical Discourse Studies, 14(3), 227-235. doi: 10.1080/17405904.2017.1284683

Bengtsson, M. (2016). How to plan and perform a qualitative study using content analysis. NursingPlus Open, 2, 814.

Bradford, A. (2015). Internationalization policy at the genba: Exploring the implementation of social science Englishtaught undergraduate degree programs in three Japanese universities [Doctoral dissertation]. George Washington University.

https://www.academia.edu/11785725/Internationalization_Policy_at_the_Genba_Exploring_the_Implementatio n_of_Social_Science_English-Taught_Undergraduate_Degree_Programs_in_Three_Japanese_Universities accessed May 1, 2019.

Burgess, C. (2010). The 'illusion' of homogeneous Japan and national character: Discourse as a tool to transcend the 'myth' vs. 'reality' binary. Asia Pacific Journal, Japan Focus, 8(9). https://apjjf.org/-ChrisBurgess/3310/article.html

Chen, Y.-W. \& Collier, M. J. (2012). Intercultural identity positioning: Interview discourses from two identity-based nonprofit organizations. Journal of International and Intercultural Communication, 5(1), 43-63. https://doi.org/10.1080/17513057.2011.631215

Dearden, J. (2014). English as a medium of instruction-a growing global phenomenon. British Council.

Dimitrov, R. (2008). The strategic response: an introduction to non-profit communication. Third Sector Review, 14(2), Special issue: The Third Sector and Communication, 9-50.

Fairclough, N. (1989). Language and power. Longman.

Hackney, R. \& Pillay, J. (2002). Organisational mission statements: A Postmodernist perspective on the management of the IS/IT function. Information Resources Management Journal, 15(1), 28-37. https://www.researchgate.net/publication/27399122_Organisational_Mission_Statements_A_Postmodernist_Per spective_on_the_Management_of_the_ISIT_Function

Haddad, M. A. (2007). Politics and volunteering in Japan: A global perspective. Cambridge University Press.

Horie, M. (2015). Japan. In H. de Wit, F. Hunter, L. Howard \& E. Ergon-Polak (Eds.) Internationalisation of Higher Education (pp. 229-240). European Parliament. http://www.europarl.europa.eu/RegData/etudes/STUD/2015/540370/IPOL_STU\%282015\%29540370_EN.pdf

Hsieh, H.-F. \& Shannon, S. E. (2005). Three approaches to qualitative content analysis. Qualitative Health Research, 15(9), 1277-1288. https://doi.org/10.1177/1049732305276687

Ivanova, P. (2020). Civil society groups involved with international students in Japan: Typology and social capital generation, Nonprofit Policy Forum, 11(3) https://doi.org/10.1515/npf-2019-0058

Johnson, R. B. \& Christensen, L. (2014). Educational research: Qualitative, quantitative and mixed approaches (5th ed.). Sage.

Knight, J. (2004). Internationalization remodeled: Definition, approaches and rationale. Journal of Studies in International Education, 8(1). https://journals.sagepub.com/doi/pdf/10.1177/1028315303260832

Knight, J. (2008). Higher education in turmoil: The changing world of internationalization. Global Perspectives on Higher Education, Vol. 13. Sense Publishers. https://www.sensepublishers.com/media/475-higher-education-inturmoil.pdf

Kyoto City (April 15, 2020). Ryūgakusei shien jigyō [International student support project]. Page number 98832. https://www.city.kyoto.lg.jp/sogo/page/0000098832.html

Kyoto City (March 25, 2014). Kyotoshi kokusai-ka suishin puran "Tabunka ga ikidzukumachi o mezashite" kaichōban no sakutei [Revised version of "Kyoto City Internationalization Promotion Plan-Aiming for a Multicultural City"]. Page number 164035. https://www.city.kyoto.lg.jp/sogo/page/0000164035.html 
Lawless, B. (2012). Ending poverty? Critical interrogations of class subjectivities, agency, and ideologies in discursive and embodied texts from a U.S. nonprofit [unpublished doctoral dissertation]. University of New Mexico.

Lin, A. (2014). Critical discourse analysis in applied linguistics: A methodological review. Annual Review of Applied Linguistics, 34, 213-232, doi: 10.1017/S0267190514000087.

Macaro, E., Curle, S., Pun, J., An, J., \& Dearden, J. (2018). A systematic review of English medium instruction in higher education. Language Teaching, 51(1), 36-76.

Ministry of Economy, Trade and Industry (METI). (April 5, 2019). New support measures for active participation of highly-skilled foreign professionals in mid-ranking enterprises and SMEs. https:/www.meti.go.jp/english/press/2019/0405_001.html accessed May 7, 2020.

Ministry of Economy, Trade and Industry (METI). (December 25, 2018). METI and JETRO Embark on New Portal Website "Open for Professionals": Attracting More Highly-skilled Foreign Professionals. https://www.meti.go.jp/english/press/2018/1225_001.html accessed May 7, 2020.

Mock, J., Kawamura, H. \& Naganuma, N. (Eds.) (2016). The impact of internationalization on Japanese higher education: Is Japanese Education Really Changing? Global Perspectives on Higher Education. Sense Publishers.

Morphew, C. C. \& Hartley, M. (2006). Mission statements: A Thematic analysis of rhetoric across institutional type. The Journal of Higher Education, 77(3), 456-471. http://muse.jhu.edu/article/196947

Ninomiya, A., Knight, J. \& Watanabe, A. (2009). The past, present, and future of internationalization in Japan. Journal of Studies in International Education, 13(2), 117-124. https://doi.org/10.1177/1028315308331095

Ogawa, A. (2009). The failure of civil society? The third sector and the state in contemporary Japan. State University of New York Press.

Otmazgin, N. K. (2018). The chrysanthemum and the cool: cultural diplomacy and soft power in Japan's foreign policy. In M.M. McCarthy (Ed.), Routledge Handbook of Japanese Foreign Policy (pp. 55-70). Routledge.

Pandey, S., Kim, M. and Pandey, S. K. (2017). Do mission statements matter for nonprofit performance? Insights from a study of US performing arts organizations. Nonprofit Management and Leadership, 27(3), 389-410.

Patton, M.Q. (2002). Qualitative research and evaluation methods (3rd ed.). Sage Publications.

Pekkanen, R. (2006). Japan's dual civil society: Members without advocates. Stanford University Press.

Poole, G.. (2016). 'International' higher education in Japan. In J. Mock, H. Kawamura \& N. Naganuma (Eds.), The Impact of Internationalization on Japanese Higher Education: Is Japanese Education Really Changing? (pp. 207-220). Global Perspectives on Higher Education. Sense Publishers.

Rakhshandehroo, M. \& Yamamoto, B. A. (2017). A review essay on internationalization strategies in Japanese universities with a focus on English language support. Journal of Graduate School of Human Sciences, Osaka University. https://ir.library.osaka-u.ac.jp/repo/ouka/all/60570/hs43_237.pdf

Rakhshandehroo, M. (2018). A qualitative exploration of on-campus experiences of English-speaking graduate international students at a leading Japanese university. Journal of International Students, 8(4), 1831-1847. https://doi.org/10.32674/jis.v8i4.233

Reimann, K. D. (2010). The rise of the Japanese NGOs: Activism from above. Routledge

Schwarz, F. J. \& Pharr, S. J. (2003). The state of civil society in Japan. Cambridge University Press.

Shimauchi, S. (2017). English-medium degree programs in internationalization of Japanese universities: Conceptual models and critical issues. Journal of Asia-Pacific Studies, 29, $105-117$. https://core.ac.uk/download/pdf/144469670.pdf

Shimauchi, S. (2018). English-medium instruction in the internationalization of higher education in Japan: Rationale and issues. Educational Studies in Japan: International Yearbook, 12, 77-90. https://files.eric.ed.gov/fulltext/EJ1182867.pdf

Souder, L. (2016). A review of research on nonprofit communications from mission statements to annual reports. VOLUNTAS: International Journal of Voluntary and Nonprofit Organizations, 27(6), 2709-2733.

Stevens, C. S. (1997). On margins of Japanese society: volunteers and the welfare of the urban underclass. Routledge. 
Takeuchi, M. (2006). The reinforcement of cultural nationalism in Japan: An investigation of Japaneseness and 'the Notebook for the Heart'. Paper presented at Japan Studies Association of Canada (JSAC) 2006 Conference, Thompson River University, Kamloops, BC, Canada, October 12-15, 2006. https://tru.arcabc.ca/islandora/object/tru\%3A1421/datastream/PDF/view

Tsujinaka, Y. (2010). Civil society and social capital in Japan. In International Encyclopedia of Civil Society (Vol. 1, 252-258). Springer.

Vinken, H., Nishimura, Y., White, B.L.J. \& Deguchi, M. (Eds.). (2010). Civic engagement in contemporary Japan: Established and emerging repertoires. Nonprofit and civil society studies series. Springer.

Vogt, G., \& Lersch, P. (2007). Migrant support organizations in Japan: A mixed-method approach. Japan 2007: Politik, Wirtschaft und Gesellschaft, Muenchen: Iudicium: 265-285. https://www.dijtokyo.org/doc/JJB_2007_Vogt_Lersch_FINAL.pdf

Wodak, R. (2007). Pragmatics and critical discourse analysis: A cross-disciplinary enquiry. Pragmatics and cognition, 15(1), 203-225.

Woolford, A. \& Curran, A. (2012). Community positions, liberal dispositions: Managing nonprofit social services within the bureaucratic field. Critical Sociology, 39(1), 45-63. https://www.academia.edu/1793661/Community_Positions_Neoliberal_Dispositions_Managing_Nonprofit_Soc ial_Services_Within_the_Bureaucratic_Field

Yanagita, K. (1910) 2008. The legends of Tono. Ronald A. Morse (Trans.). Lexington Books. 


\section{APPENDIX A}

List of Japanese CSOs in the Study

Himeji Cultural and International Exchange Foundation http://www.himeji-iec.or.jp/e jigyo.html

Kyoto City International Foundation: What is the Kyoto City International Foundation http://www.kcif.or.jp/web/en/foundation/about/

KyoTomorrow Academy https://www.studykyoto.jp/kyotomorrowacademy/en/

Miki International Association: Our Story: https://www.facebook.com/mikiinternational/

Nagahama International Friendship Association http://www.nifa.jp/

Nishinomiya City International Association:

https://www.nishi.or.jp/shisei/seisaku/tabunkakyosei/nia/aboutnia/nia.html

Osaka University International Student Association: About

https://www.facebook.com/pg/OUISA.OU/about/?ref=page_internal

Ritsumeikan GSA: see Appendix 1

Ritsumeikan OIC TISA: About https://www.facebook.com/pg/oictisa/about/?ref=page_internal

Suita International Friendship Association: About SIFA https://suita-sifa.org/en/about-sifa-english/

The Yasu International Friendship Association: About http://yifashiga.org/english/access/ 


\section{APPENDIX B}

Ritsumeikan GSA mission statement is available online only on internal university messaging to current students and not accessible outside university.

[Important] Announcement of the opening of the application for the position of New GSA Committee Members

\section{December $18^{\text {th }} 2018$ Name (omitted for privacy reasons) / Election officer}

The Graduate School Association (GSA) is pleased to announce the opening of the application for the position of GSA Committee Members for the academic year 2019- 2020.

According to the organization within the Graduate School of International Relations, the students are convened to elect their representatives to represent their interests to the various entities across the university.

About the GSA The Graduate School Association is an official organization which mission is to represent and defend the student's interests within the Graduate School of International Relations of Ritsumeikan University. Its main role is summarized as follows:

1. To act as an intermediary between the graduate students and the Administrative office.

2. To ensure that social life of the students within the department will go smoothly and in harmony.

3. To intervene whenever it is needed on all issues related to the students' life. 